\title{
Penerapan Psikologi Arsitektur pada Fasilitas Pendidikan anak Usia Dini dan SeKolah Dasar di Kota Surakarta
}

\author{
Tri Suci $\mathbf{H}^{1^{*}}$, Tri Yuni ${ }^{2}$, Leni Pramesti ${ }^{3}$ \\ Program Studi Arsitektur, Fakultas Teknik, Universitas Sebelas Maret ${ }^{1}$ \\ E-mail : trschdy@gmail.com* \\ Program Studi Arsitektur, Fakultas Teknik, Universitas Sebelas Maret ${ }^{2}$ \\ Program Studi Arsitektur, Fakultas Teknik, Universitas Sebelas Maret ${ }^{3}$
}

\begin{abstract}
Psychological architecture is a field of study that studies the relationship between built environment and human behavior, which mutually affect one another. The built environment and human behavior, especially in early childhood, will be closely related because in this period, children have not been able to develop their own potential, so that the environment will greatly affect the development of children's potential. This study aims to know how the psychology of architecture applied in the Preschool and Elementary building. The application of psychological architecture in this building is done through the design in accordance with the children's characteristics, by connecting the characteristics and theories of psychological architecture. The result of application can be seen in users, activities, site, space, and building mass.
\end{abstract}

Keywords: psychological architecture, early childhood education, surakarta

\section{PENDAHULUAN}

Pendidikan merupakan aset penting bagi kemajuan bangsa Indonesia, sehingga setiap warga negara harus dan wajib mengikuti jenjang pendidikan. Pelayanan kebutuhan pendidikan setelah anak lahir dimulai dari lingkungan keluarga, namun di era modern kini terdapat pergeseran peran dan fungsi keluarga yang berpengaruh terhadap edukasi dan perkembangan anak usia dini. Pendidikan Anak Usia Dini (PAUD) adalah suatu upaya pembinaan yang ditujukan kepada anak sejak lahir sampai dengan usia enam tahun melalui pemberian rangsangan pendidikan untuk membantu pertumbuhan dan perkembangan jasmani dan rohani (Undang-undang Nomor 20 Tahun 2003 tentang Sistem Pendidikan Nasional pada Bab I pasal 1, angka 14 ).

Hakikat anak usia dini adalah individu yang unik yang memiliki pola pertumbuhan dan perkembangan dalam aspek fisik, kognitif, sosioemosional, kreativitas, bahasa dan komunikasi yang khusus yang sesuai dengan tahapan yang sedang dilalui oleh anak tersebut (Augusta, 2012). Masa anak usia dini merupakan masa emas, dimana anak belum bisa mengembangkan potensi diri sendiri. Dengan demikian, dibutuhkan upaya dalam bidang pendidikan guna mencapai pengembangan potensi dan perkembangan anak yang optimal, yang meliputi perkembangan fisik dan psikis

Pendidikan anak menjadi salah satu program dari Kota Surakarta sebagai salah satu Kota Layak Anak. Kementrian Pemberdayaan Perempuan dan Perlindungan anak telah menunjuk enam kota sebagai Kota Layak Anak (KLA) pada tahun 2006, yang salah satunya adalah Kota Surakarta. Kota Layak Anak (KLA) adalah Kabupaten/Kota yang mempunyai sistem pembangunan berbasis hak anak melalui pengintegrasian komitmen dan sumber daya pemerintah, masyarakat dan dunia usaha untuk menjamin terpenuhinya hak anak (Permen No.11 Tahun 2011).

Angka partisipasi kasar (APK) PAUD di Kota Solo yang menunjukkan partisipasi penduduk yang sedang mengenyam pendidikan sesuai dengan jenjang pendidikannya pada tahun 2014 sebesar 84,16\%, masih kurang dari target Pemerintah Kota Solo yang presentasenya mencapai $90 \%$, sehingga perlu adanya 
peningkatan APK PAUD Kota Surakarta (Badan Pusat Statistik Surakarta 2014).

PAUD dan SD merupakan salah satu lembaga atau fasilitas pendidikan yang membantu menumbuh kembangkan ilmu dan potensi dasar dari siswa atau peserta didik. Tidak hanya dalam aspek ilmu dan intelektual, akan tetapi juga dalam aspek kepribadian, tingkah laku, tata krama dan budi pekerti juga diajarkan di fasilitas pendidikan tersebut. PAUD dan SD sebagai fasilitas pendidikan tidak hanya memberi nilai-nilai akademik atau peringkat pada siswa, namun juga memiliki fungsi untuk memberikan pelayanan membimbing, mendidik dan mengajar para peserta didik agar memiliki sifat atau tingkah laku yang lebih baik.

Psikologi arsitektur adalah sebuah bidang studi yang mempelajari hubungan antara lingkungan binaan dan perilaku manusia, dimana keduanya saling mempengaruhi antara satu dengan yang lain. Tujuan bidang ini adalah untuk mengatasi masalah yang menyangkut interaksi manusia dengan lingkungan sehingga mampu menciptakan perilaku yang diinginkan (Deddy Halim: 2005). Psikologi arsitektur menjadi penting untuk digunakan sebagai metoda pendekatan desain pada pendidikan anak usia dini dan sekolah dasar, karena memiliki daya dukung ilmu psikologi dalam menciptakan lingkungan binaan, yang mampu menghasilkan respon berupa perilaku yang diingkinkan berupa perkembangan yang sesuai dengan karakteristik anak.

\section{METODE}

Metode yang digunakan pada perancangan Pendidikan Anak Usia Dini dan Sekolah Dasar adalah penerapan psikologi arsitektur. Psikologi arsitektur adalah sebuah bidang studi yang mempelajari hubungan antara lingkungan binaan dan perilaku manusia. Tujuan bidang ini untuk mengatasi masalah yang menyangkut interaksi manusia dengan lingkungan sehingga mampu menciptakan perilaku yang diinginkan. (Deddy Halim: 2005)

Psikologi arsitektur sebagai pendekatan desain pada Pendidikan Anak Usia Dini dan Sekolah Dasar didasarkan atas daya dukung ilmu psikologi arsitektur dalam menciptakan lingkungan binaan, yang mampu menghasilkan respon berupa perilaku. Respon atau perilaku yang diinginkan merupakan perkembangan yang sesuai dengan karakteristik anak, sehingga karakteristik anak digunakan sebagai stimulus yang kemudian membentuk setting ruang.

Penerapan psikologi arsitektur dalam bangunan Pendidikan Anak Usia Dini dan Sekolah Dasar dilakukan melalui perancangan sesuai karakteristik anak. Per ancangan sesuai karakteristik dilakukan dengan menghubungkan karakteristik anak dengan teori psikologi arsitektur, sehingga akan dihasilkan output berupa rancangan bentuk dan setting ruang.

\section{HASIL DAN PEMBAHASAN}

Penerapan psikologi arsitektur dalam bangunan Pendidikan Anak Usia Dini dan Sekolah Dasar dilakukan dengan menghubungkan karakter anak dan teori psikologi arsitektur. Beberapa karakteristik anak adalah bersifat unik, egosentris. Karakteristik anak antara lain adalah aktif, dinamis, eksploratif, memiliki rasa ingin tahu yang tinggi,memiliki daya konsentrasi pendek, dan belajar melalui permainan (Sofia Hartati, 2005). Teori psikologi arsitektur yang digunakan yaitu lima unsur pokok yang menghubungkan disiplin ilmu arsitektur dan psikologi, yaitu arketipe, kepribadian, gender, anatomi fisik, dan psikofisik (Dedy Halim, 2005).

Penerapan psikologi arsitektur dalam bangunan Pendidikan Anak Usia Dini dan Sekolah Dasar dapat dikelompokkan menjadi beberapa bagian, yaitu pengguna dan kegiatan, tapak, ruang, serta bentuk dan tampilan bangunan.

3.1 Pengguna dan Kegiatan

Penggunaan psikologi arsitektur sebagai pendekatan desain didasarkan atas daya dukung ilmu psikologi arsitektur dalam menciptakan lingkungan binaan, sehingga terlebih dulu harus dilakukan pengelompokan pengguna dan kegiatan sehingga lingkungan binaan dapat diciptakan sesuai kondisi psikologis kelompok pengguna. 
Tabel 1. Pengguna, Kegiatan dan Luas Ruang

\begin{tabular}{|l|l|c|}
\hline Pengguna & Kegiatan & Ruang \\
\hline $\begin{array}{l}\text { Peserta didik } \\
\text { (KB, TK, SD, } \\
\text { Kursus) }\end{array}$ & Pendidikan & $2.727 \mathrm{~m}^{2}$ \\
\hline Anak Asuh & Pengasuhan & $188 \mathrm{~m}^{2}$ \\
\hline $\begin{array}{l}\text { Pengunjung } \\
\text { - Akademisi, } \\
\text { praktisi, } \\
\text { orangtua, } \\
\text { masyarakat } \\
\text { peserta } \\
\text { didik baru } \\
\text { tenaga } \\
\text { medis }\end{array}$ & Penunjang & $233 \mathrm{~m}^{2}$ \\
\hline $\begin{array}{l}\text { Pengelola } \\
\text { Kepala }\end{array}$ & & \\
$\begin{array}{l}\text { Pengelola, } \\
\text { Kepala } \\
\text { Program, Staff } \\
\text { dan karyawan) }\end{array}$ & & \\
\hline Total & Pengelola & $518,5 \mathrm{~m}^{2}$ \\
\cline { 2 - 3 } & & $4.066 \mathrm{~m}^{2}$ \\
& & \\
\hline
\end{tabular}

\subsection{Pemilihan dan Perancangan Tapak}

Anak memiliki daya konsentrasi yang rendah, sehingga dalam pemilihan tapak, karakteristik anak menjadi salah satu pertimbangan. Dengan daya konsentrasi yang cenderung rendah, maka tapak yang dipilih harus berada di lokasi dengan tingkat kebisingan rendah, misalnya di wilayah permukiman. Pemilihan tapak juga dilakukan dengan melakukan perbandingan antara jumlah anak usia dini dan fasilitas yang ada di setiap kecamatan di Kota Surakarta dan perbandingan paling kecil berada di Kecamatan Serengan. Tapak terpilih berada di wilayah pemukiman warga yaitu di Jalan Pandu Dewanata, Serengan, dengan luas tapak $\pm 15.318 \mathrm{~m}^{2}$.

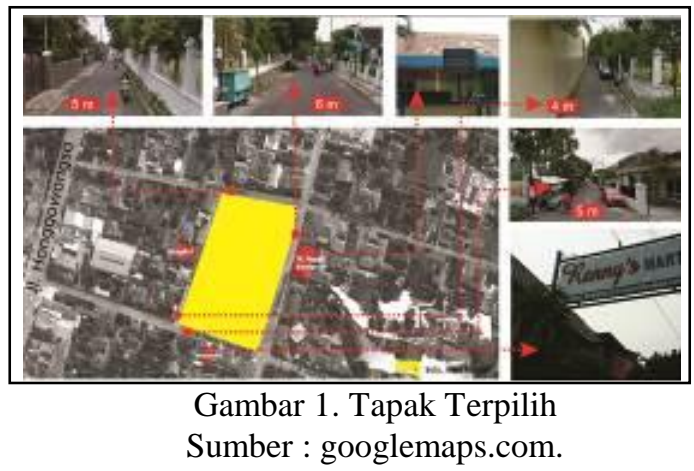

Pencapaian ke dalam site harus jelas dan memberikan kenyamanan pengunjung dengan kemudahan pencapaian dan tidak mengganggu penguna dalam bangunan, sehingga letak main entrance (ME) sehingga ME diletakkan agak jauh dengan bangunan pendidikan, sebagai respon dari kebisingan yang ditimbulkan oleh kendaraan yang masuk dan melakukan manuver dalam site, sehingga kenyamanan pengguna dan konsentrasi anak yang rendah tetap terjaga.

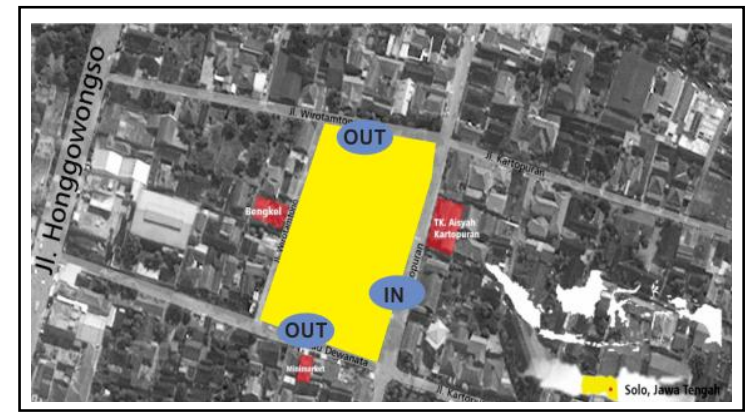

Gambar 2. Pencapaian pada Site.

\subsection{Ruang}

Anak belajar melalui permainan, sehingga ruang kelas pada kegiatan pendidikan anak usia dini akan berbentuk sentra. Penataan ruang pada ruang-ruang pendidikan akan disesuaikan dengan keadaan psikologis dan karakteristik anak. Anak usia dini akan memiliki tatanan ruang yang lebih dinamis dan tidak teratur, sedangkan ruang bagi anak usia sekolah dasar akan lebih formal. Ruang outdoor akan dilengkapi dengan elemen permainan bagi anak.

\subsection{Bentuk, Tata Massa dan Tampilan Bangunan}

Perancangan massa meliputi bentuk, tata massa, dan tampilan bangunan.

Bentuk dan Tampilan BangunanBentuk yang dipilih terkait dengan karakteristik anak usia dini yang memiliki karakteristik aktif, dinamis dan eksploratif, sehingga gubahan massa mengambil bentuk lingkaran yang mewakili gerakan dinamis, dan dipadukan dengan persegi dan unsur garis-garis vertikal dan horizontal agar bangunan tidak bersifat kaku namun tetap terlihat formal (DK. Ching, 1994).

Tata Massa Bangunan

Bangunan yang dirancang terdiri dari beberapa massa yang tersusun secara terpusat agar kegiatan dapat dipantau oleh pihak pengelola, 
sehingga keamanan anak lebih terjamin. Setiap massa bangunan memiliki pola sirkulasi yang berbeda, antara lain linear dan grid.

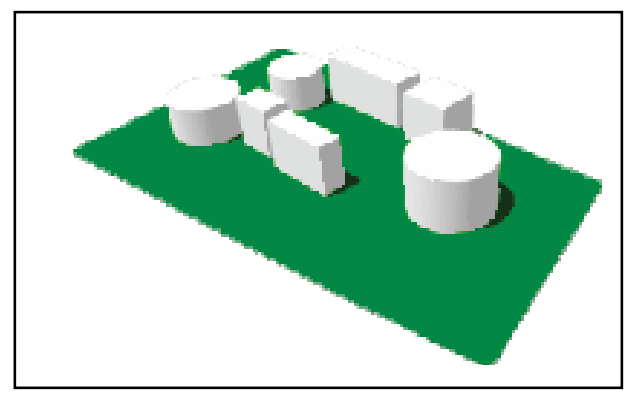

Gambar 3. Tata Massa Bangunan

Tampilan Bangunan

Psikologi arsitektur yang diterapkan merupakan hasil dari karakteristik anak yang dihubungkan dengan teori unsur psikologi.

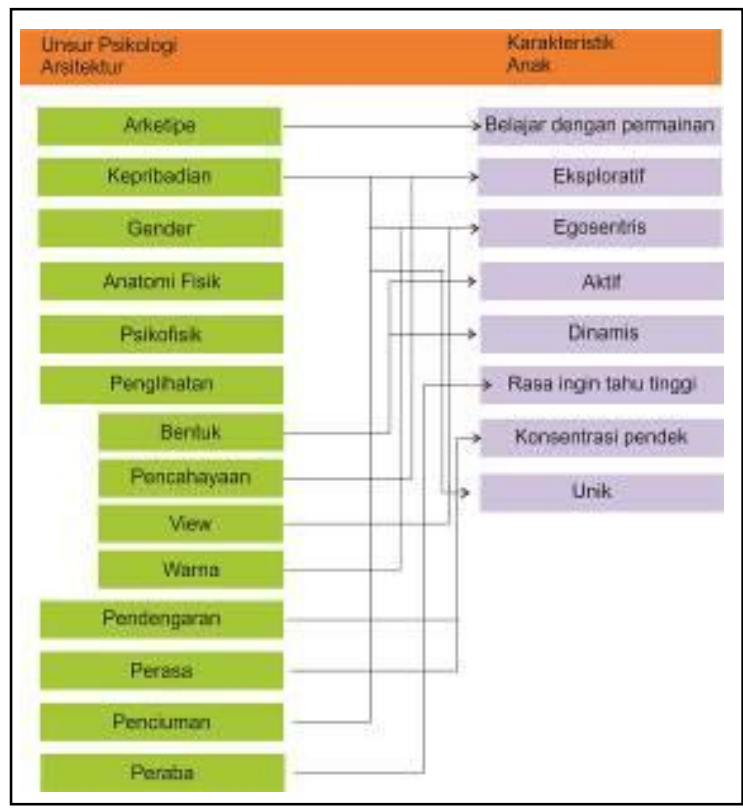

Skema 1. Pola Hubungan Karakteristik Anak dan Unsur Psikologi Arsitektur

Dari pola hubungan di atas, maka diperoleh hasil tampilan sebagai berikut :

- Ruang kelas berbentuk sentra, terdapat elemen permainan pada bangunan.

- Menggunakan bentuk universal berupa lengkungan dengan kombinasi garis tegas.

- Memberikan kesan unik pada bagian atas bangunan.
- Bentuk dinamis dari lengkungan dan pengulangan jarak/ dimensi/ bentuk yang berbeda.

- Konfigurasi melingkar dengan lapangan di tengah sehingga anak dapat aktif dan leluasa bergerak.

- Pencahayaan alami dengan material kaca (eksploratif).

- Ruang kelas dengan material kaca pada beberapa bagian sebagai gambaran eksploratif terbuka pada pengetahuan.

- View ke arah taman memberikan efek menenangkan dan meningkatkan kreativitas.

- Warna sesuai setting yang akan dibuat, menggunakan warna cerah hijau dan biru, warna primer merah dan kuning, serta warna netral abuabu.

- Bukaan sesuai arah angin, pemberian green roof.

- Penggunaan material beragam sehingga mendapat tekstur yang beragam.

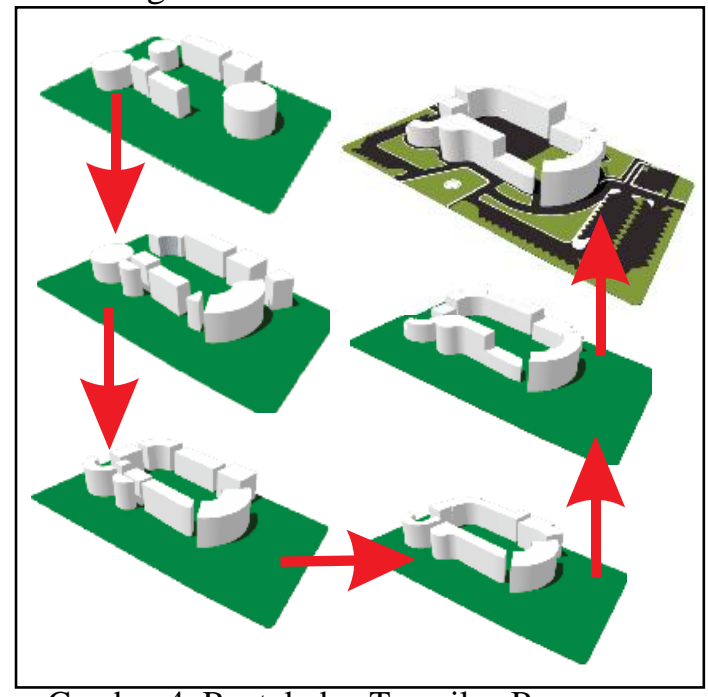

Gambar 4. Bentuk dan Tampilan Bangunan

\section{KESIMPULAN}

Penerapan Psikologi Arsitektur pada fasilitas Pendidikan Anak Usia Dini dan Sekolah Dasar dilakukan dengan menggabungkan karakteristik anak dengan teori psikologi arsitektur, sehingga dihasilkan output yang digunakan sebagai acuan dasar dalam perancangan. Fasilitas Pendidikan Anak Usia Dini dan Sekolah Dasar merupakan fasilitas 
pendidikan berjenjang yang terdiri dari Taman Penitipan Anak (TPA), Kelompok Belajar (KB), Taman Kanak-kanak (TK), kursus, dan Sekolah Dasar (SD).

Penerapan psikologi arsitektur dalam bangunan Pendidikan Anak Usia Dini dan Sekolah Dasar yang direncanakan adalah sebagai berikut :

A. Pengguna dan Kegiatan

Pengelompokan pengguna dan kegiatan dilakukan agar lingkungan binaan yang akan diciptakan dapat sesuai dengan kondisi psikologis kelompok pengguna. Kelompok pengguna dan kegiatan pada bangunan Pendidikan Anak Usia Dini dan Sekolah Dasar adalah sebagai berikut:

Tabel 2. Kelompok Pengguna dan Kegiatan

\begin{tabular}{|l|l|}
\hline Pengguna & Kegiatan \\
\hline Peserta didik & Pendidikan \\
\hline Anak Asuh & Pengasuhan \\
\hline Pengunjung & Penunjang \\
\hline Pengelola & Pengelolaan dan Servis \\
\hline
\end{tabular}

\section{B. Tapak}

Sesuai dengan sifat anak yang memiliki konsentrasi rendah, tapak berada di wilayah pemukiman warga dengan Main Entrance $(M E)$ yang jelas dan jauh terletak agak jauh dari zona pendidikan agar tidak mengganggu konsentrasi anak.

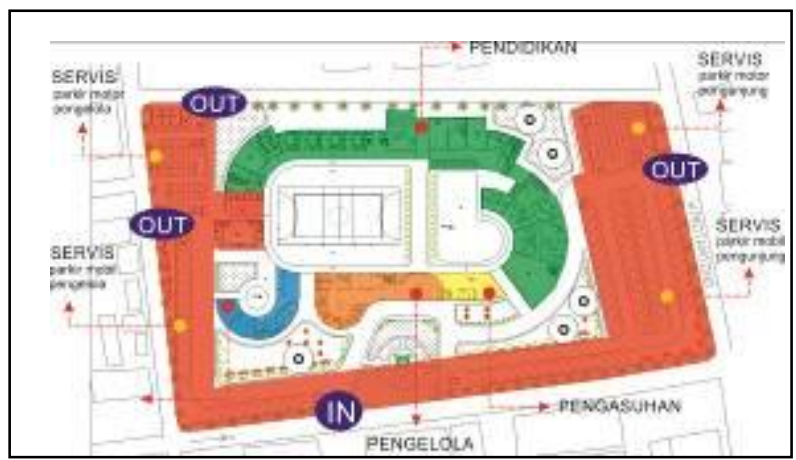

\section{Ruang}

Gambar 5. Pengolahan Tapak

Anak usia dini memiliki karakteristik aktif dan dinamis, sehingga tatanan ruang anak akan berbeda dengan ruang anak usia sekolah dasar. Anak usia dini akan memiliki tatanan ruang yang dinamis dan tidak teratur, sedangkan ruang bagi anak usia sekolah dasar akan lebih formal.

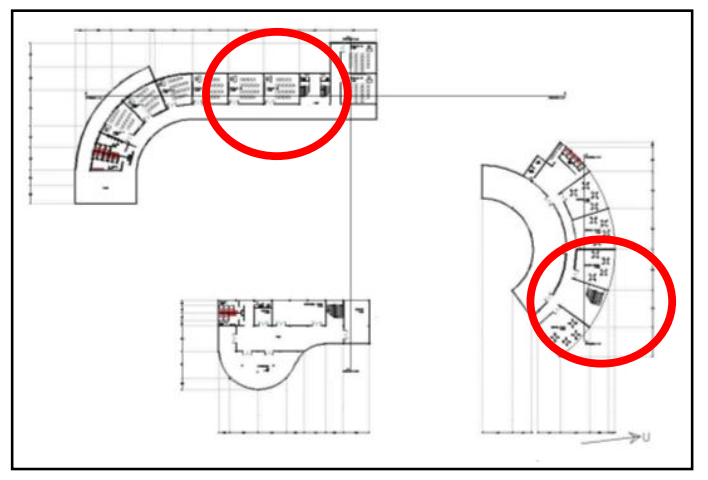

Gambar 6. Ruang Kelas PAUD (kanan) dan SD (kiri)

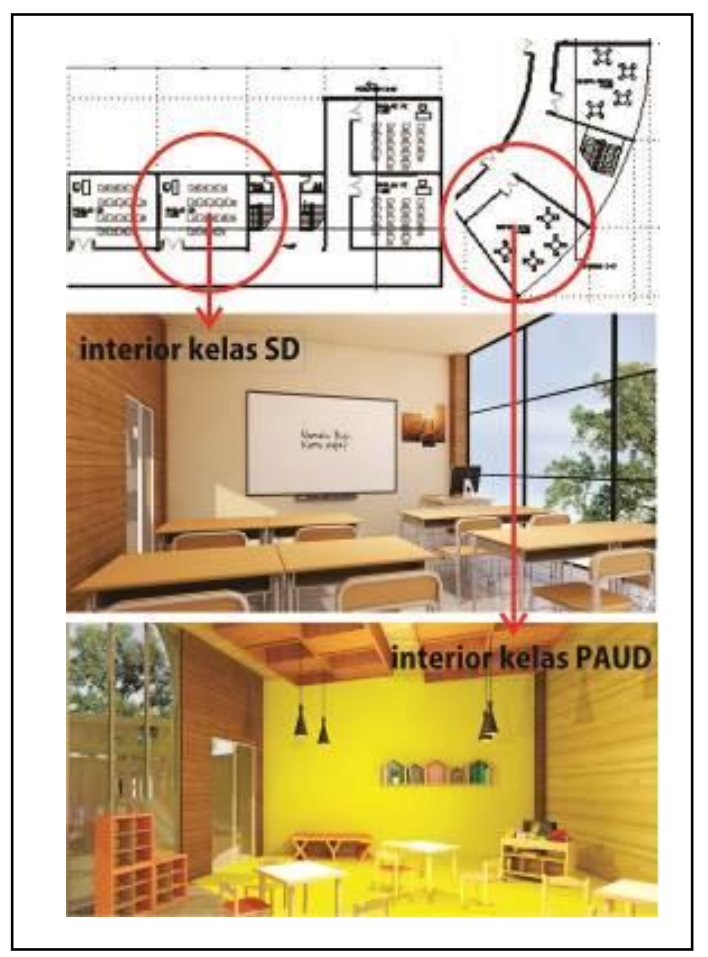

Gambar 7. Perbedaan Tatanan Ruang Kelas PAUD dan SD

D. Massa

Bentuk, tampilan, dan susunan massa bangunan Pendidikan Anak Usia Dini dan Sekolah Dasar sesuai pola hubungan karakteristik dan unsur psikologi arsitektur adalah sebagai berikut :

\section{Aktif}

Anak memiliki karakteristik aktif sehingga dalam perancangan diwujudkan dengan area bermain terbuka yang luas berbentuk lingkaran di area tengah, sehingga anak dengan leluasa dapat melakukan kegiatan secara aktif dan tetap berada dalam pengawasan. 


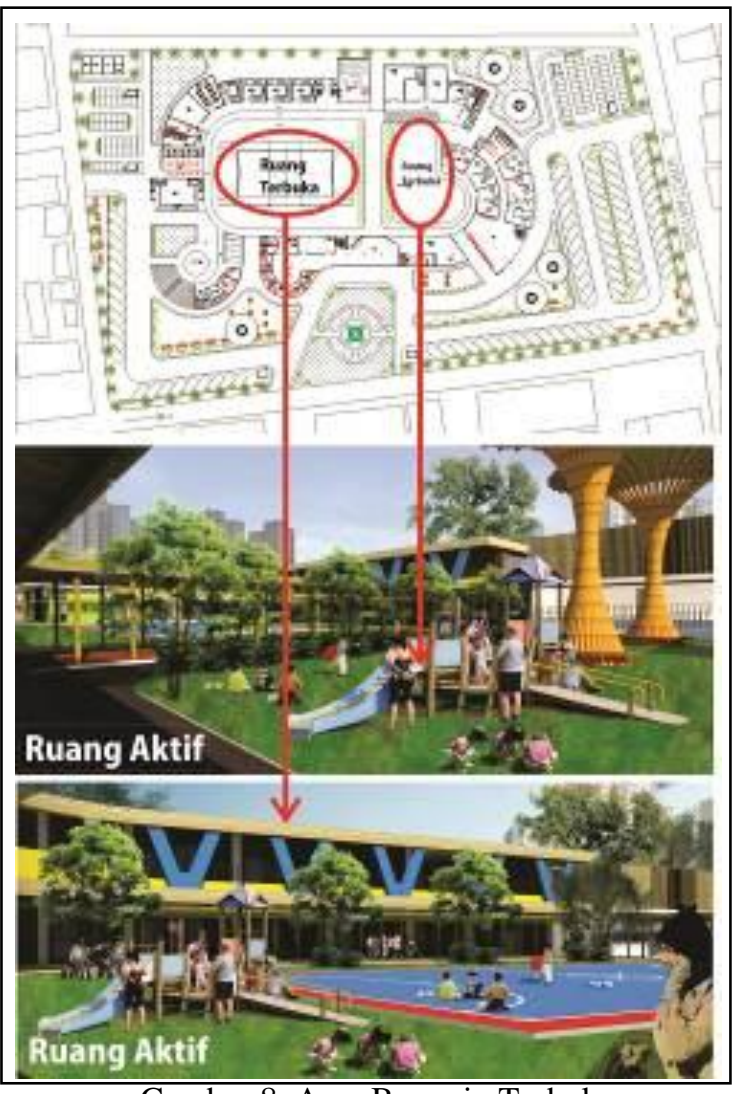

Gambar 8. Area Bermain Terbuka

\section{Dinamis}

Karakteristik anak yang dinamis ditampilkan melalui pengulangan bentuk atau garis dengan perletakan, jarak, atau dimensi yang berbeda memberikan irama dinamis sesuai dengan karakteristik anak usia dini.

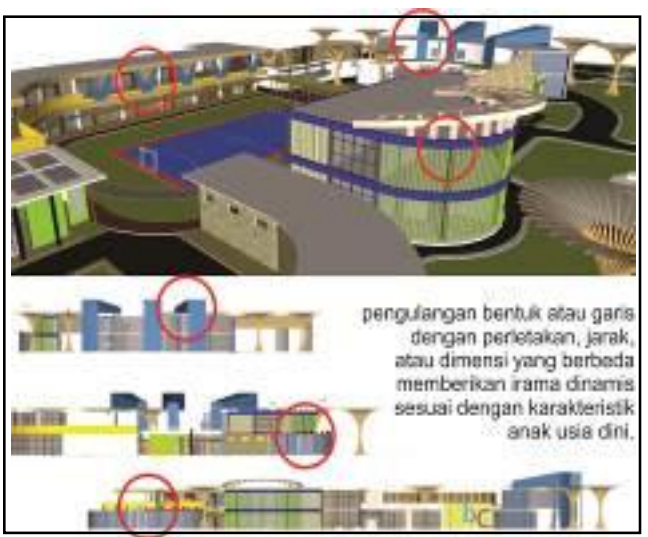

Gambar 9. Kesan Dinamis Bangunan

\section{Eksploratif}

Penggunaan berbagai macam material dan warna dengan tujuan mewadahi dan menunjang karakteristik anak yang eksploratif sehingga anak dapat mengenal berbagai macam material dan warna. Selain itu, digunakan material kaca pada beberapa bagian sebagai penggambaran eksploratif atau terbuka pada pengetahuan.

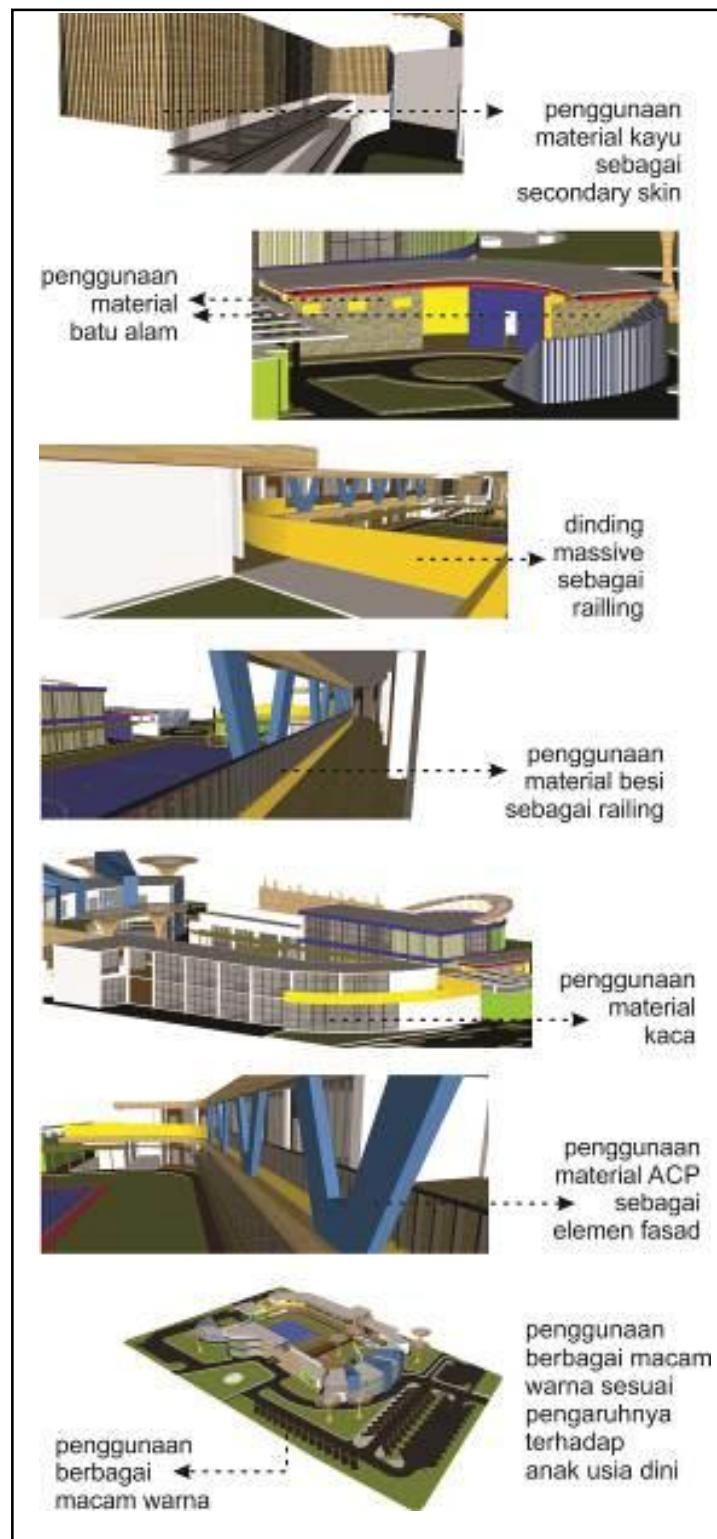

Gambar 10. Penggunaan Berbagai Material

\section{REFERENSI}

Badan Pusat Statistik Kota Surakarta. 2014. Kota Surakarta Dalam Angka. Surakarta: BPS Surakarta.

Ching, Francis D.K. 1994. Arsitektur, Bentuk Ruang \& Susunannya. Jakarta: Erlangga.

Halim, Dedy. 2005. Psikologi Arsitektur. Jakarta: Grasindo. 
Hartati, Sofia. 2005. Perkembangan Belajar pada Anak Usia Dini. Jakarta: Depdiknas.

Peraturan Menteri No.11 Tahun 2011

Undang-Undang No.20/2003 tentang Sistem Pendidikan Nasional Bab I pasal 1, angka 14.

https://googlemaps.com/, diakses 2 Maret 2017. 